\title{
La escenificación de las relaciones entre el rey y los consejeros en don Juan Manuel
}

The staging of the relations between the king and councilors in don Juan Manuel

José Ángel Salgado Loureiro

DOI: https://doi.org/10.24215/23468971e121

Universidad de Santiago de Compostela, España

asalgado.loureiro@gmail.com

Recepción: 20 Abril 2020

Aprobación: 09 Junio 2020

\section{Resumen:}

En la presentación de la trama de El libro del caballero y el escudero (1326) y de El libro de los estados (1327-1330) de don Juan Manuel, se desarrollan escenas en las que participan las figuras del rey y los consejeros. A través de ello se prefiguran pautas e ideas sobre la importancia de la figura del consejero regio, un tema frecuente entre los textos didáctico-políticos castellanos de finales del siglo XIII e inicios del XIV. En la escenificación inicial de estas dos obras podemos ver cómo don Juan Manuel proyectó, a inicios del reinado de Alfonso XI, unos valores político-culturales cuyo origen se localiza en el conflictivo e inestable reinado de Fernando IV. Palabras Clave: El libro del caballero y el escudero, El libro de los estados, Don Juan Manuel, «molinismo», Consejo y consejeros.

\section{Abstract:}

During the presentation of the plot of El libro del caballero y Escudero (1326) and El libro de los estados (1327-1330) by don Juan Manuel certain scenes unfold in which the figures of both king and he's councilors are involved. Through this, norms and ideas of the importance of the figure of the royal councilor are foreshadow, a recurrent topic throughout the political-didactical Castilian texts of the end of the XIIIth and the beginning of the XIVth Century. In the initial staging of both books we can observe how don Juan Manuel projected, in the early reign of King Alfonso XI, certain political-cultural values whose origins are in the unstable and conflicted reign of King Fernando IV.

KEYwORDS: El libro del caballero y el escudero, El libro de los estados, Don Juan Manuel, «molinismo», Council and Councilors.

Una buena parte de la producción textual de don Juan Manuel se inserta dentro de la larga tradición de obras didácticas de contenido político que se desarrolló con fuerza en la Corona de Castilla, especialmente a partir del siglo XIII. Algunos especialistas han observado que todos los textos «juanmanuelinos»revierten, en conjunto, un destacado valor didáctico orientado a la reproducción de los valores de la nobleza. ${ }^{1}$ Ahora bien, podemos identificar un núcleo de obras de especial significación política que se aproximan a la tipología textual de los espejos de príncipe; entre otros, analizados por F. Gómez Redondo (1998, p. 1111); H. Tracy Sturcken (1974, p. 105) y M. J. Lacarra, (2006, p. 36). Estas obras, compuestas en la segunda etapa de producción literaria de nuestro autor, que se desarrolla a partir de 1326, serían El libro del caballero y el escudero, El libro de los estados, El libro del conde Lucanor y El libro enfenido. De entre todas ellas, El libro del caballero y el escudero y El libro de los estados aportan algunas consideraciones que nos permiten aproximarnos a la comprensión de don Juan Manuel sobre las relaciones que se establecen entre el rey y sus consejeros.

La raíz ideológica del pensamiento político de don Juan Manuel se localiza en lo que algunos autores han denominado como el «molinismo». Entre los autores destacados que han analizado el concepto se encuentran F. Gómez Redondo (2012) y H. O. Bizzarri (2001, p. 432 y 439-444) y de L. Funes (2014) para los casos concretos de Sancho IV y de Fernando IV. Un marco cultural que se desarrolló en la Corona de Castilla de mano de los reyes Sancho IV y doña María de Molina, y que se extendió, como mínimo, hasta la declaración de la mayoría de edad de Alfonso XI en 1325. Uno de los aspectos que definieron este marco 
cultural en lo político fue, precisamente, la importancia de la figura del consejero y su relación con el poder regio. Cabe notar también que, junto con este marco cultural, el propio desarrollo de los acontecimientos políticos durante todo el reinado de Fernando IV y el comienzo del reinado de Alfonso XI, entre finales del siglo XIII e inicios del XIV, parecen haber reforzado estas consideraciones sobre la importancia del consejo y los consejeros. ${ }^{2}$ En ambos casos, el de Fernando IV y el de Alfonso XI, don Juan Manuel jugó un papel destacado como actor político de su tiempo, siendo uno de los principales defensores de los privilegios de la nobleza \#el estudio biográfico completo disponible es el de A. Giménez Soler (1932). El principal objetivo de este trabajo es el de estudiar la representación de algunos valores e ideas políticas relativas al tema del consejo y los consejeros a través de la escena inicial que abre los relatos de «El libro del caballero y el escudero» y de «El libro de los estados». Para ello, nos aproximaremos primeramente a las formas de representación de esta temática en la tradición textual didáctico-política «molinista»en la que se inserta don Juan Manuel. Después estudiaremos cómo se escenifica el tema del consejo y los consejeros en la trama inicial de «El libro del caballero y el escudero $\gg$ y de «El libro de los estados». Una vez hecho esto, apuntaremos algunas de las cuestiones del contexto histórico y biográfico de don Juan Manuel que podrían ayudar a comprender el cómo y el porqué de su discurso sobre los consejeros y el rey.

\section{LA ESCENIFICACIÓN DEL TEMA DEL CONSEJO Y LOS CONSEJEROS EN LOS TEXTOS MOLINISTAS EN EL TIEMPO DE DON JUAN MANUEL}

Situado el inicio del marco «molinista en el reinado de Sancho IV, podemos ver que durante este tiempo se produce una proliferación de textos didácticos con marcado contenido político (Sylvie, 2017). A pesar de las diferencias que presentan entre ellos, se puede observar que todos fueron compuestos bajo los mismos principios ideológicos y culturales (Bizarri, 2001). Entre estos textos se pueden identificar con bastante certeza títulos como Castigos y documentos del rey Sancho IV, el Lucidario, el Libro del Tesoro, la Versión retóricamente amplificada de 1289, o el Barlaam y Josafat.

La situación varió ligeramente durante el reinado de Fernando IV, entre 1301 y 1312, periodo en el que no se conoce patrocinio regio de la producción cultural. Ahora bien, como ha demostrado Leonardo R. Funes, esto no significa que el "impulso molinista" no se mantuviese, sino que pervivió seguramente gracias a la labor de doña María de Molina. L. Funes (2014) identificó, al menos, veintiséis textos «molinistas» en este periodo, principalmente crónicas de diferente índole (p. 531-538). No obstante, también debemos tener en cuenta que la proliferación de crónicas no implica la desaparición de los textos didáctico-políticos, de los cuales podemos identificar, como mínimo, dos obras que también se podrían localizar cronológicamente en este tiempo. Estas serían, por un lado, «El libro del caballero Zifar», definido por F. Gómez Redondo como la culminación tardía de la ideología política «molinista» de corte regio, y que se puede situar con cierto grado de imprecisión en el primer tercio del siglo XIV. Por el otro lado estaría el caso más polémico de «El libro del consejo y los consejeros», que tradicionalmente ha sido asimilado a la producción cultural de Sancho IV, en torno al año 1293. Ahora bien, siguiendo a algunos autores como Barry Taylor \#y más recientemente $S$. Robert, 2017\# se podría situar algunos años más tarde, entre 1306 y 1336. En base a esta cronología, en lugar de considerarlo como resultado tardío de la producción de Sancho IV, debería entenderse como un producto relacionado con el contexto político e ideológico de Fernando IV. Ambos textos, «El libro del caballero Zifar»y «El libro del consejo y los consejeros», serían, por lo tanto, contemporáneos a don Juan Manuel.

De forma general se ha aceptado la idea de que el consejo y los consejeros fue uno de los temas políticos centrales de la producción textual «molinista». Entre el reinado de Sancho IV y la minoría de edad de Alfonso XI, la nobleza castellana fue adquiriendo gran fuerza hasta el punto de poder imponer sus exigencias al poder real, situación \#durante el reinado de Fernando IV\# que ha sido estudiada por C. González Mínguez (2004, pp. 238-241). La reflexión sobre el consejo y otros aspectos del ámbito cortesano parece ser una consecuencia de la necesidad de delimitar, de forma teórica, un marco de actuación que regulase las relaciones 
entre el poder regio y los nobles; entre los autores que han apostado por esta consideración destacan $\mathrm{H}$. O. Bizzarri y A. Rucquoi (2005, p. 31) o P. Rochwert-Zuili (2011, pp. 943-944). De este modo, una de las funciones de la literatura didáctico-política castellana de este periodo habría sido el establecimiento de modelos a seguir por parte de la nobleza, introduciendo temáticas relativas al ámbito cortesano y a los consejeros (Nogales Rincón, 2006, pp. 10-11).

La centralidad temática del consejo resulta evidente en el caso de «El libro del consejo y los consejeros». Sobre ello, Fernando Gómez Redondo afirmó que, en el marco «molinista», se acaba

\begin{abstract}
“convirtiendo la naturaleza del consejo y la figura del consejero en el centro de una nueva relación política. (...) el consejero adquiere una relevante posición por el valor de dirigir el pensamiento del rey; (...). De este trasfondo de ideas, surge una de las secuencias argumentales imprescindibles en los primeros textos de ficción que comienzan a construirse en este momento y que muestra al rey reunido con su grupo de consejeros, escuchando su parecer antes de tomar una decisión" (Gómez Redondo, 1998, p.946)
\end{abstract}

En la obradestacan aspectos de la relación rey-consejo que parecen ser de consideración principal, como el secretismo, la prudencia y la necesidad de saber escoger bien a los consejeros. Se presentan también algunas cualidades básicas que éstos deben poseer, como que tengan buena reputación, que sean sabios y experimentados, de carácter firme y que sean amigos del rey, de modo que lo aconsejen de forma honesta y sincera (Sylvie, 2017). Por otra parte, en el caso de «El libro del caballero Zifar» se ha hecho notar la importancia de este tema por parte de autores como Patricia Rochwert-Zuili (2011). Ésta observó que, entre las cuestiones relativas a los consejeros, se tratan, por un lado, las cualidades que deben tener, como el buen seso o el entendimiento (Rochwert-Zuili, 2011) y, por el otro, la forma en que se debe escoger a los consejeros, buscando siempre la "amistad verdadera" (Rochwert-Zuili, 2011). Recogiendo las consideraciones de estos autores se puede apreciar cierta unidad y homogeneidad en el enfoque desde el que se trata el tema del consejo entre los textos «molinistas».

Ya en su momento, F. Gómez Redondo (1999) observó que don Juan Manuel recogía muchas de estas consideraciones al estudiar su encaje en el marco ideológico y cultural del «molinismo» (p. 839). Ahora bien, para comprender cómo nuestro autor trata el tema del consejo, debemos observar la forma en que se desarrolla el discurso político en los textos «molinistas» por los que habría sido influido. Estos textos no se produjeron a modo de tratados, sino a modo de historias de ficción didáctica que servían para establecer un sistema de valores políticos. En muchas de ellas cobró especial relevancia la función del diálogo entre los personajes, no sólo a nivel estético o formal, sino también temático-estructural. Se generaron, así, "imágenes de ficción" que prefiguraban ideas políticas concretas. ${ }^{3}$ En este sentido llamamos la atención sobre la observación de Leonardo R. Funes en su estudio sobre "las letras castellanas en tiempos de Fernando IV", donde apuntó que uno de los rasgos característicos de la producción literaria de inicios del siglo XIV fue la imposición de la escenografía por encima de la narratividad. Esto es, que en los textos «molinistas» "no interesa tanto contar una historia, sino más bien mostrar una escena, desplegar una situación” (Funes, 2014, p.538) a través de la que se delimita una teoría política determinada.

A partir de esta anotación podemos afirmar que a través de la escenificación política de los diferentes relatos se prefiguran, a la vez que se reproducen, valores ideológicos sobre la realidad política. Estos valores e ideas políticas no siempre tienen que ser coincidentes entre sí. Se puede observar cierto grado de variación y divergencia entre ellos según la inclinación ideológica que adquiera cada texto en función del autor y el contexto de producción. De este modo, siguiendo la línea planteada, estudiaremos cómo se escenifica el pensamiento político de don Juan Manuel en lo tocante al consejo y a los consejeros en la presentación de la trama inicial que abre los relatos de «El libro del caballero y el escudero»y de «El libro de los estados». Aquí tenemos en cuenta que, para hablar de política, cualquier sujeto recurre a las concepciones, temas y formas discursivas precedentes de la tradición cultural en la que se inserta. ${ }^{4}$ Así, situado don Juan Manuel dentro del marco cultural del «molinismo» y de la tradición del didactismo político castellano, comprenderemos sus ideas en relación con la producción textual de dicho marco. 


\section{LA ESCENIFICACIÓN DE LAS CORTES Y EL CONSEJO DEL REY COMO ESPACIO DE DECISIONES POLÍTICAS EN EL LIBRO DEL CABALLERO Y EL ESCUDERO}

«El libro del caballero y el escudero»es un texto didáctico-político de temática caballeresca compuesto en forma dialogada en torno al año 1326. Su composición, que podría haber comenzado en 1325, se desarrolla durante un periodo en el que don Juan Manuel pasa de alcanzar el pináculo de su poder al servicio del recién coronado Alfonso XI, a entrar en un conflicto armado con este rey que se prolongaría hasta 1338 (Giménez Soler, 1932, pp. 83-112). Entre las causas de dicho conflicto estuvo la renovación de las élites nobiliarias que rodeaban y aconsejaban a Alfonso XI. Con ello, destacados ricohombres como el propio don Juan Manuel, que hasta entonces había jugado un papel protagonista en la política castellana, se vieron desplazados del poder ante el ascenso de otros nobles menores como Alvar Núñez de Osorio o Garcilaso de la Vega.

En la trama del texto intervienen dos personajes principales, un joven escudero que, de camino a las cortes del rey, se encuentra con un caballero anciano que lo instruye sobre diferentes materias relativas a la orden de caballería, la política y la fe católica. La instrucción impartida por el caballero se divide en dos partes. La primera está dedicada a la materia propiamente caballeresca. En base a la aplicación de lo aprendido, el escudero puede aconsejar correctamente al rey en las cortes, gracias a lo cual es recompensado con el título de caballero, así como con honras y riquezas. Más tarde, vuelve a junto del caballero anciano para proseguir con la segunda parte de su formación, que versa sobre temas variados orientados a comprender la realidad del hombre en el mundo como parte de la Creación de Dios.

La materia relativa al tema del consejo y los consejeros no se trata de forma explícita. Como se ha indicado más arriba, es una cuestión que se desarrolla de forma indirecta a través de la escenificación del relato. Podemos localizarla en la presentación de la trama inicial, al comienzo del texto ${ }^{5}$ y al final de la primera parte de la formación del escudero, finalizado el episodio de las cortes del rey. En el primer caso, a la hora de presentar la historia se habla de un reino innominado en el que gobierna un rey bueno y exitoso. La clave de su éxito como gobernante, tal y como lo presenta don Juan Manuel, reside en que ejerce un tipo de poder semicompartido con sus nobles, escuchando sus consejos a través de la celebración de cortes. Este rey aparece definido a través de virtudes como la nobleza, la justicia y el buen seso. Todas ellas hacen referencia a algún aspecto de la relación entre el rey y los nobles que lo aconsejan.

La nobleza se entiende como una virtud política que lleva al rey a no actuar de forma despótica, sino teniendo en consideración a las gentes de su señorío. Bajo este aspecto se definen dos parámetros esenciales de la conducta regia en el ejercicio de su gobierno. Primero, la ejecución de un tipo de gobierno semicompartido y, segundo, el respeto por la ley establecida, esto es, por los fueros y leyes que los reyes anteriores habían otorgado. Lo que nos interesa aquí como objeto de estudio es la relación del rey con otros sujetos políticos que intervienen en las labores de gobierno, véase, la nobleza. Así, prestaremos atención a la primera cuestión por la que se define la nobleza del rey, como es la celebración de Cortes:

\footnotetext{
"dize en el comienço de aquel libro que en una tierra avía un rey muy bueno y muy onrado, y que fazía muchas buenas obras, todas segund pertenecía a su estado; y por mostrar la su nobleza, fazía muchas vezes sus cortes ayuntar, a que venían muchas gentes de sus tierras y de otras. (...) Y a toda la tierra en general daba buenas leis y buenos fueros, y mantenía y guardávales muy bien lo que avían de los otros reis que fueren ante que él” (Don Juan Manuel, 2014, p.270)
}

Al presentarlo como un síntoma de nobleza, don Juan Manuel comprende que la celebración de cortes no es una obligación, sino que es el rey quien decide celebrarlas, mostrando con ello una cualidad propia de lo que considera como el modelo de buen gobernante.

La segunda virtud que destaca en el planteamiento de don Juan Manuel es la justicia. Para que el rey se pueda considerar como un gobernante justo debe observar dos cuestiones. Por un lado, debe saber castigar a los malhechores, impartiendo penas según el castigo y, por el otro, también ha de saber recompensar a aquellos que lo sirven útil y correctamente: 
"y de que con él, fazíales mucho bien, dando algo de lo suyo muy granadamente a los que lo devía dar, tan bien a los estraños como a los suyos (...). Y esto era con muy grant razón, ca los sus naturales eran seguros de aver d'él buen galardón del servicio quel fazían, aún más que non merecían. (...) Otrosí sabían que el que mal o daño en su tierra fiziesse, non podría en ninguna manera escapar d'él sin grant pena" (Don Juan Manuel, 2014, p.270)

Se presenta así una doble comprensión de la justicia, a la vez punitiva y retributiva, bastante generalizada en la época y que también estará presente en «El libro de los estados». ${ }^{6}$

El aspecto de la justicia en el que don Juan Manuel parece hacer mayor hincapié es, precisamente, el retributivo. Esto no resulta casual si atendemos a la escena que se presenta entre las dos partes de la exposición didáctica del caballero anciano, cuando el escudero actúa como consejero en las cortes y recibe a cambio grandes honras y beneficios:

“el escudero fue para las cortes y andiedo tanto por sus jornadas que llegó aquel lugar do el rey fazía sus cortes. Y endereçol Dios así: que cuando él llegó a ver las cortes, non eran partidas, y cuando mostró al rey la su razón por que viniera y otrosí le contó la aventura que le acaeciera en el camino con el cavallero hermitaño, tomó el rey y todos los que eran con él muy grant plazer; y entre cuantos ý binieron a aquellas cortes, fízol el rey mercedes muy señaladas. Y tanto se pagó de las sus buenas maneras quel tovo consigo grant pieça de tiempo, y fízol cavallero y después embiolo a su tierra muy rico y muy onrado" (Don Juan Manuel, 2014, p.297)

Podemos notar aquí cómo la escenificación planteada por don Juan Manuel prefigura una idea fundamental a la hora de delimitar la naturaleza de la relación entre el rey y sus consejeros; a saber, la recompensa al buen servicio como síntoma de justicia.

La tercera virtud presentada, el buen seso, se relaciona con la cuestión anterior de la recompensa al buen servicio. Se trata de una cualidad intelectiva que se presenta como una virtud política determinante a la hora de determinar la buena o mala actuación de los actores políticos:

"otrosí, el buen seso le es muy mester, ca el seso le amostrará quién es el que puede y lo deve fazer cavallero; y otrosí el que á de recebir la cavallería; y otrosí qué es lo que el cavallero deve guardar a Dios y a su señor y a las gentes, y qué onra le deven fazer a él, y otrosí la que él deve fazer a sí mismo. Otrosí le demostrará qué es lo que deve dar y qué es lo que deve tener" (Don Juan Manuel, 2014, p.74)

Buena parte de la importancia de esta virtud reside en que, sin ella, no se puede llevar a cabo un gobierno justo, ya que el rey carecería de un criterio firme y objetivo a partir del cual determinar cómo premiar y castigar a los nobles que lo aconsejan.

Por otra parte, en base a la posesión de este buen seso, el rey sabrá también diferenciar entre los buenos consejeros, que buscan el bien del reino, y aquellos que aconsejan de forma deshonesta, buscando el beneficio personal o el mal para otros terceros. En «El libro del caballero y el escudero», don Juan Manuel se refiere a estos últimos como "mezcladores":

“y non recelavan que por ningún mezclador les vernía ningún daño sin grant su merecimiento. (...). Y por estas cosas era muy amado y muy recellado; y tan grant sabor avían las gentes del servir, que non dudavan de poner los cuerpos y los averes por levar su onra adelante, y tenían que la muerte y la lazeria en su servicio les era vida y folgura. Y las gentes estrañas deseavan que diesse Dios razón por que ellos, guardando su lealtad, pudiessen seer en el su señorío” (Don Juan Manuel, 2014, p.274)

\section{LA RELACIÓN ENTRE EL REY, EL CONSEJO Y LOS CONSEJEROS EN LA APERTURA DEL RELATO DE El LIBRo DE LOS ESTADOS}

«Ellibro de los estados»es, también, una obra didáctica de marcado contenido político compuesta en estilo dialogado en la que intervienen cuatro personajes. La mayor parte de la acción transcurre a través de la interacción de los dos personajes principales, el infante Joás y su instructor el clérigo Julio. Junto con ellos aparecen, al inicio de la historia, el rey Morabán y el consejero Turín, que a su vez es, también, instructor del infante Joás. El texto, compuesto entre 1327 y 1330, es la obra inmediatamente posterior a «El libro del 
caballero y el escudero». Se inserta, por lo tanto, en el marco del recrudecimiento del conflicto entre don Juan Manuel y Alfonso XI.

En la presentación de la trama inicial el infante Joás aparece como el heredero de un reino pagano innominado, que vive intelectualmente aislado del conocimiento sobre el dolor y la tristeza en el mundo. El encargado de criarlo y mantenerlo en este estado de ignorancia de la realidad es el consejero Turín, un hombre de confianza del rey Morabán. Cierto día, a raíz de un encuentro fortuito con un difunto, Turín se ve obligado a rebelar al infante las realidades de la muerte y el alma, incumpliendo su palabra para con el Rey. Tal revelación provoca un profundo estado de inquietud en el infante, que solicita a su padre, el rey Morabán, que le facilite un nuevo instructor. Este será Julio, un clérigo castellano que procede al adoctrinar a infante en la fe católica, provocando con ello la conversión de todo el reino al cristianismo.

La prefiguración de ideas políticas referentes al tema del consejo y los consejeros en «El libro de los estados»se produce entre los capítulos III y XIX, en los que se presenta la escena inicial, justo antes de la aparición del personaje del clérigo Julio. ${ }^{8}$ La escena se desarrolla a través de la conversación entre los personajes de Joás, Turín y Morabán. Por un lado, la conducta del rey Morabán prefigura algunos valores o virtudes que éste ha de tener a la hora de tratar con sus consejeros, como la prudencia y la comprensión. Por el otro, en el diálogo entre el rey y Turín se exponen las cualidades que debe poseer un buen consejero, así como la forma en que se ha de conformar y de escuchar al consejo.

Como se ha indicado, cuando el consejero e instructor Turín revela al infante Joás las realidades de la muerte y el alma, incumple el mandato del rey Morabán. A pesar de que la desobediencia está justificada por la insistencia del infante, Turín permanece en un estado de gran inquietud, temeroso de las posibles represalias por su desobediencia. Por este motivo solicita la intercesión del infante en su favor cuando se dirigen al rey para pedir un nuevo instructor: "señor, agora vos he dicho toda la verdat en estos fechos, y, por mi pecado, he fecho todo lo contrario de lo que me fue mandado, mas, pues non fue por mi culpa, pídovos por merced que non olvidedes de me guardar de daño" (Don Juan Manuel, 2014, p.344).

Cuando el infante intercede por Turín para evitar que sea castigado por desobediencia, el rey lo escucha atentamente. Hecho esto, Morabán opta por no reprender al que es su consejero de confianza y el criador de su hijo:

“-señor (dixo el infante), yo agradesco a Dios y a vós esto que me dizides, es pues tanta merced me prometedes, tened por
bien de me fazer otra; que querades fazer merced y galardonar a Turín por la criança que en mí ha fecho, y por el trabajo que
tomó en mio servicio, y non tomedes enojo, nin sospechedes que él nunca fizo cosa que fuese contra el vuestro mandado.
El rey le dixo que así lo creía, y quel aseguraba que así lo faría como el infante gelo pidía. -Señor (dixo el infante), pues esto
me prometedes y só cierto que vós sodes tal que non faredes ninguna cosa contra lo que una vegada prometedes, agora vos
contaré toda mi voluntad y todo lo que me acaeció. Entonce le contó todo lo quel acaeciera con Turín, (...)" (Don Juan
Manuel, 2014, p.345)

De este modo, podemos ver que el rey Morabán se caracteriza por virtudes como a prudencia y la comprensión, de tal modo que escucha las alegaciones antes de emitir un juicio precipitado castigando la desobediencia de Turín.

A partir de ahí, el diálogo se desarrolla entre Morabán y Turín, sucediendo que el primero solicita al segundo que lo aconseje sobre cómo encontrar al mejor instructor posible para Joás. A la hora de exponer el motivo por el cual Turín está obligado a dar consejo, el rey Morabán expone las cualidades básicas que se deben buscar en el buen consejero. En primer lugar, el consejero debe ser alguien que mantenga una relación de deuda con el rey, de modo que siempre quiera responder lealmente a los favores recibidos. En segundo lugar, debe ser un buen conocedor de la hacienda regia, pues sólo así podrá proponer medidas realistas y eficaces. Debe, también, poseer buenas aptitudes intelectuales, así como ser una persona de gran confianza y de destacada sinceridad, no ocultando nada de lo que sabe. Por último, debe mantener una relación tan estrecha con el rey que reciba el mismo daño o beneficio que su señor a raíz del consejo que ofrece: 
"ca en todo consejo granado que el señor demanda, el vasallo á mester ý seis cosas: la una es que el consejero que aya recebido tantos bienes del señor por que sea tenudo del amar y de aver grant cuidado de los sus fechos; la segunda, que sepa mucho de su fazienda; la tercera, que sea de muy buen entendimiento; la cuarta, que sea de muy grant poridat; y la quinta, que sepa todo aquel fecho y non le encubra ende nada; la sesta, que siga al consejero mesmo pro o daño, si el consejero se errare o se acertare" (Don Juan Manuel, 2014, p.347)

De igual modo, el propio Turín, a la hora de exponer las cualidades que habrá de tener el nuevo instructor, presenta algunas virtudes personales que son aplicables a la figura del consejero, como la bondad y las buenas capacidades intelectuales: "y lo que a mí parece que devíades fazer es que catásedes algún omne muy letrado y muy entendido, y que fuese omne de buena entención y derechurero, y sin malicia, (...)” (Don Juan Manuel, 2014, p.350)

De igual modo, se especifica, también por boca del rey Morabán, cómo se ha de componer el consejo, que no debe constar de más de dos o tres miembros. La justificación de esta afirmación se da a partir de que, si se llama a más consejeros, puede que algunos nobles que se tienen por iguales a estos se sientan ofendidos por no ser llamados. Así mismo, en el caso de incluir a demasiados miembros en el consejo para que ninguno se vea agraviado, difícilmente se podrán tomar decisiones y mucho menos guardar el secreto de las cuestiones tratadas.

\footnotetext{
"Cuando el señor llama a su consejo tantos que pasan de dos o tres, por fuerça á de llamar a muchos aquel consejo. Ca los omnes, tan bien en estados y en onras como en privanças, son llegados los unos a los otros, y cuando el señor llama a cuatro o cinco a su consejo, los que se tienen por eguales de alguno de aquellos tiénense por agraviados, si non llaman a ellos. Y el señor, por guardar esto, álos a llamar, y los otros que non son llamados, y se tienen por eguales de aquellos, agrávianse ende, y por fuerça abrán a seer llamados, o fincan despagados. (...) Y demás que es cierto que deque a los consejos viníen atantos, que non puede ser guardada poridat. Y por ende entiendo que en consejo granado, en que aya mester grant poridat, que nunca deve el señor llamar a él sinon dos o tres a lo más” (Don Juan Manuel, 2014, pp.348-349)
}

Acto seguido Turín solicita el rey Morabán que exponga sus consideraciones, de modo que pueda seguir su opinión: "-Señor (dixo Turín), si la vuestra merced fuese, a mí ploguiera mucho, y aun tengo que sería razón que dixiésedes vós primero vuestra voluntat” (Don Juan Manuel, 2014, p.349). A esto responde el rey con una breve explicación sobre cómo debe ser tomado el consejo. Se indica que el rey debe ser el último en exponer su punto de vista por dos razones. Primero, porque habiendo escuchado lo que sus consejeros tienen que decir, podrá razonar mejor su exposición. Segundo, que, en caso de hablar el rey primero, los consejeros tenderán a darle la razón con el fin de congraciarse con él, resultando de ello un consejo poco operativo:

“-Turín (dixo el rey), por dos razones, en los consejos de pocos o de muchos, deve el señor oír ante lo que los otros dizen: la una es porque desque oyó a los otros, mejor entiende lo que cumple en aquel consejo; la otra es que si el señor dize primeramente cuál es su voluntad, por aventura los consejeros querrán ante seguirla y non se atreverán a dezir contra ello, y así podría fincar el consejo errado. Por ende, vos mando que digades vós primero vuestro entendimiento, ca ý se me finca a mí para dezir después lo que yo entendiere por mejor” (Don Juan Manuel, 2014, p.349)

\section{El TRATAMIENTO DEL TEMA DEL CONSEJO Y LOS CONSEJEROS Y SU RELACión CON LA EXPERIENCIA POLÍTICA DE DON JUAN MANUEL}

Como se ha visto hasta aquí, tanto «El libro del caballero y el escudero» como «El libro de los estados» se produjeron uno inmediatamente después del otro. Son, por tanto, el resultado de una misma realidad política, pero que no deja de ser una realidad cambiante, en constante proceso de evolución histórica. El tratamiento que se da al tema del consejo y los consejeros se puede relacionar con el contexto en el que se encontraba don Juan Manuel a la hora de componer sus obras.

En «El libro del caballero y el escudero» se presenta al rey como un gobernante noble a partir del hecho de que cuenta con la nobleza en el ejercicio del poder a través de la celebración de cortes. Este fue un rasgo característico de la política de Fernando IV, que buscó siempre la resolución de los conflictos nobiliarios que 
asolaron Castilla a través del pactismo y la integración de los nobles castellanos en el aparato gubernativo y administrativo de la Corona (Correa, 2016). Siendo contemporáneo a estos sucesos, don Juan Manuel jugó un papel destacado en dichos enfrentamientos nobiliarios, logrando casi siempre un notable beneficio personal, así como desempeñó oficios señalados como el de adelantado del Reino de Murcio o mayordomo del rey. También la celebración frecuente de Cortes fue otro de los rasgos definitorios del gobierno de Fernando IV \# esto puede verse en G. Santamaría Torquemada, 1988, p. 299. En este sentido, la corresponsabilidad entre el rey y la nobleza en el ejercicio del poder parece haber sido un rasgo ideológico destacado de la producción «molinista». ${ }^{9}$ De este modo, podemos observar que las consideraciones de don Juan Manuel sobre la relación entre el rey y los consejeros se hunden en un bagaje cultural y en una experiencia política personal que se insertan en el marco cultural de la Castilla de finales del siglo XIII.

Ahora bien, cabe destacar aquí una divergencia entre lo que don Juan Manuel vivió y lo que escribió. Nos referimos al hecho de que sólo se refiera a la nobleza como consejeros, cuando un aspecto llamativo de la política de Fernando IV fue la imposición, por parte de las Hermandades, de un consejo permanente de doce «omnes buenos», miembros de las aristocracias urbanas que habrían de guiar y condicionar las decisiones políticas \#cuestión que ha sido tratada, entre otros, por M. Asenjo González (1997, p. 137); M. A. Martín Romera (2018, p. 94) y A. Álvarez de Morales (1974, p. 46). Se trata, seguramente, de una omisión voluntaria que funcionaría como recurso discursivo para orientar la narración hacia los principios ideológicos ${ }^{10}$ de los grandes ricohombres castellanos. De este modo, cuando compuso «El libro del caballero y el escudero» a inicios del reinado de Alfonso XI, don Juan Manuel estaría proyectando un modelo político ideal desde su perspectiva ideológica personal, marcadamente nobiliaria, que se habría forjado en la confluencia de la producción político-cultural «molinista» con las prácticas políticas de Fernando IV en la primera década del siglo XIII.

De igual modo, podemos ver que en «El libro de los estados» destacan cualidades del buen rey como la prudencia y la comprensión. Estas se presentan como virtudes esenciales para el correcto funcionamiento de un órgano como el consejo regio, de modo que el rey no castigue precipitadamente a los nobles que lo sirven y sepa ver en ellos la buena intención y las buenas aptitudes intelectuales. Así, el desarrollo de la escena inicial del texto se puede relacionar con el contexto de don Juan Manuel durante el tiempo de redacción, ya que a partir de 1326-1327, los nuevos consejeros de Alfonso XI condicionan las decisiones del rey castellano motivando la rebelión armada de nuestro autor (Giménez Soler, 1932, pp.83-87) Siguiendo la terminología planteada en la obra anterior, «El libro del caballero y el escudero», desde la perspectiva de don Juan Manuel los nuevos consejeros regios podrían ser catalogados como "mezcladores". Observamos, así, que don Juan Manuel recurrió tanto a la temática como a la tipología textual propia de las obras didáctico-políticas «molinistas» para articular un discurso sobre las relaciones entre el rey y los consejeros. En él proyecta como modelo ideal las conclusiones extraídas de su propia experiencia política durante el reinado de Fernando IV, oponiéndolo a los sucesos que vive con Alfonso XI durante el tiempo de composición.

\section{CONCLUSIón}

Los diferentes aspectos en base a los que se estudia la construcción y representación del poder regio en los textos didáctico-políticos castellanos no han de ser entendidos como puntos definidos, o como compartimentos estancos. Al contrario, son dimensiones de una comprensión culturalmente compartida de la política que, según el caso concreto (del texto, del autor y del contexto de producción), adquieren matices ideológicos concretos. Así, para comprender la cuestión del consejo y los consejeros en «El libro del caballero y el escudero»y en «El libro de los estados», es necesario prestar atención a otros rasgos del poder regio, como pueden ser las relaciones del rey con la ley, con el pueblo y, de forma más algo más concreta, con la nobleza.

Como se ha indicado, durante el tiempo de Sancho IV proliferó la producción de textos didáctico-políticos que se mantuvo durante el reinado de Fernando IV, quizás con menos vigor y gracias al impulso de doña 
María de Molina. De ello habrían resultado títulos como «El libro del consejo y los consejeros» y «El libro del caballero Zifar». Algunos años más tarde, ya a inicios del reinado de Alfonso XI, la actividad de don Juan Manuel con textos como «El libro del caballero y el escudero»y «El libro de los estados» parece haber supuesto una continuación de estas formas de textualidad política «molinista», al menos en lo tocante al tema del consejo y los consejeros.

Siguiendo el recurso a la prefiguración de ideales políticos a través de la escenografía de los relatos como forma indirecta de discurso, don Juan Manuel retoma temas ya presentes en otros textos anteriores como «El libro del consejo y los consejeros»o «El libro del caballero Zifar». A nuestro parecer, lo visto hasta aquí no parece ser argumentación suficiente como para afirmar que don Juan Manuel hubiese hecho un uso directo de estas obras para componer la suyas propias. No obstante, resulta evidente que todas ellas se insertan dentro de un mismo marco cultural e ideológico (el «molinista») que determina tanto el enfoque como el desarrollo de los temas. Se puede apreciar, así, cómo el tratamiento de cuestiones como la prudencia, el buen seso o inteligencia y la confianza son, entre otros aspectos, algunos de los puntos comunes entre todos estos textos.

No debemos ignorar el hecho de que puedan existir algunas diferencias con respecto a otros textos «molinistas» en la configuración de estos elementos dentro del discurso «juanmanuelino», así como en la aproximación a cuestiones como la mejor forma de tomar consejo o de escoger a los consejeros. Ahora bien, todas ellas parecen fácilmente explicables en base al contexto de don Juan Manuel. Esto se hace especialmente evidente si atendemos a su experiencia política previa y a la situación a la que se enfrenta durante el tiempo de composición de «El libro del caballero y el escudero» y de «El libro de los estados», enfrascado en el conflicto con Alfonso XI y sus nuevos consejeros.

\section{REFERENCIAS}

Álvarez de Morales, A. (1974). Las Hermandades: expresión del movimiento comunitario en España. Valladolid: Universidad.

Asenjo González, M. (1997). Ciudades y Hermandades en la Corona de Castilla. Aproximación sociopolítica. Anuario de estudios medievales, 27(1), 103-146. Recuperado de: http://estudiosmedievales.revistas.csic.es/index.php/est udiosmedievales/article/view/643/654

Bizzarri, H. O. y Rucquoi, A. (2005). Los espejos de príncipes en Castilla entre Oriente y Occidente. Cuadernos de historia de España, 79, 7-30. Recuperado de http://repositoriouba.sisbi.uba.ar/gsdl/cgi-bin/library.cgi?e=d-10000-00---off-0cuahisto--00-2----0-10-0--0---0direct-10----4------0-11--10-es-Zz-1---20-about---00-3-1-00-00--4----0-0-01-00-0utfZz-8-00\&a=d\&c=cu ahisto\&cl=CL2.2\&d=79-8_htm

Bizzarri, H. O. (2001). Reflexiones sobre la empresa cultural del rey Don Sancho IV de Castilla. Anuario de estudios medievales, 31(1), 429-451. Recuperado de http://estudiosmedievales.revistas.csic.es/index.php/estudiosmedie vales/article/view/287/292

Castro y Calvo, J. M. (1945). El arte de gobernar en las obras de don Juan Manuel. Barcelona: CSIC-Instituto Antonio Nebrija.

Correa, M. P. (2016). La integración de la nobleza en los oficios de la corte de Fernando IV de Castilla (1295-1312). Revista Chilena De Estudios Medievales, 9, 63-77. Recuperado de http://revistas.ugm.cl/index.php/rcem/artic le/view/90/78

Don Juan Manuel (2014). Obras completas. Valladolid: Proyecto Parnaseo.

Fernández-Ordóñez, I. (2000). Variación en el modelo historiográfico alfonsí en el siglo XIII. Las versiones de la Estoria de España. En G. Martin (ed.), La historia alfonsi: el modelo y sus destinos (siglos XII-XIV) (pp. 41-74). Madrid: Casa Velázquez.

Funes, L. R. (1988). El trabajo intertextual de don Juan Manuel y la apertura del relato en el Libro de los Estados.Journal of Hipanic Philology, 12, 103-112. 
Funes, L. (2014). Las letras castellanas en tiempos de Fernando IV: esbozo de una historia literaria. En C. Esteve (ed.), El texto infinito: tradición y reescritura en la Edad Media y el Renacimiento (pp. 529-542). Salamanca: Seminario de Estudios Medievales y Renacentistas-Sociedad de Estudios Medievales y Renacentistas.

Giménez Soler, A. (1932). Don Juan Manuel, Biografía y Estudio Crítico. Zaragoza: Academia Española.

Gómez Redondo, F. (2009). Doña María de Molina y el primer modelo cultural castellano. En M. C. Cosmen, M. V. Herráez Ortega y M. P. Gómez-Calcerrada (coords.), El intercambio artístico entre los reinos hispanos y las cortes europeas en la Baja Edad Media (pp. 29-46). León: Universidad de León.

Gómez Redondo, F. (2012). El molinismo: un sistema de pensamiento letrado (1284-1350). En A. Martínez Pérez y A. L. Baquero Escudero (coords.), Estudios de literatura medieval: 25 años de la Asociación Hispánica de Literatura Medieval (pp. 45-81). Murcia: Universidad de Murcia.

Gómez Redondo, F. (1998). Historia de la prosa medieval castellana, I. La creación del discurso prosistico: el entramado cortesano. Madrid: Cátedra.

González Mínguez, C. (2004). Fernando IV de Castilla (1295-1312) perfil de un reinado. Espacio, tiempo y forma. Serie III, 17, 223-244. Recuperado de https://dialnet.unirioja.es/servlet/articulo?codigo=1262155

González Mínguez, C. (1995). Fernando IV (1295-1312). Palencia: Olmeda.

González Mínguez, C. (2012). Poder real y poder nobiliar en la Corona de Castilla (1252-1369). Bilbao: Universidad del País Vasco.

Koselleck, R. (2006). Estructuras de Repetición en el Lenguaje y en la Historia. Revista de Estudios Politicos, 134, 17-34. Recuperado de https://dialnet.unirioja.es/servlet/articulo?codigo $=2210443$

Lacarra, M.J. (2014). Don Juan Manuel (1282-1348): orgullo nobiliario y escritura. En M. J. Lacarra (coord.), Don Juan Manuel y su producción literaria (pp. 5-15). Valencia: Proyecto Parnaseo

Lacarra, María J. (2006). Don Juan Manuel. Madrid: Síntesis.

Martín Romera, M. A. (2018). Hermanas desiguales. Las jerarquías urbanas a través de las hermandades bajomedievales. Anuario de estudios medievales, 48(1), 81-115. Recuperado de http://estudiosmedievales.revist as.csic.es/index.php/estudiosmedievales/article/view/877/887

Nogales Rincón, D. (2006). Los espejos de príncipes en Castilla (siglos XIII-XV): un modelo literario de la realeza bajomedieval. Medievalismo, 16, 9-40. Recuperado de https://revistas.um.es/medievalismo/article/view/50931 /49061

Pocock, J. G. A. (2011). Pensamiento Politico e Historia. Ensayos sobre Teoría y Método. Madrid: Akal.

Recuero Lista, A. (2016). El reinado de Alfonso XI de Castilla (1312-1350) (tesis doctoral inédita). Universidad Autónoma de Madrid. Recuperada de http://hdl.handle.net/10486/674742

Robert, S. (2017). La littérature sapientielle sous Sanche IV ou l'art de conseiller. e-Spania, 27. Recuperado de http: //journals.openedition.org/e-spania/26827

Rochwert-Zuili, P. (2011). El valor del consejo en el Libro del caballero Zifar. e-Spania, 12. Recuperado de http://jo urnals.openedition.org/e-spania/20706

Santamaría Torquemada, G. (1988). La legislación en cortes sobre la cancillería de Fernando IV: 1295-1312. En Las Cortes de Castilla y León, 1188-1988: Actas de la tercera etapa del Congreso Cientifico Sobre la Historia de las Cortes de Castilla y León (pp. 285-300). Valladolid: Simancas-Cortes de Castilla y León.

Sturcken, H. T. (1974). Don Juan Manuel. Nueva York: Twayne.

Taylor, B. (1984). Los capítulos perdidos del Libro del Cavallero et del Escudero y el Libro de la Cavallería. Incipit, 4, 51-69.

Van Dijk, T. A. (2003). Ideología y Discurso. Barcelona: Ariel.

\section{Notas}

1 Se trata de una consideración ampliamente aceptada en la historiografía del medievalismo español. Ya en 1945 José María Castro y Calvo observó a don Juan Manuel como un autor didáctico, preocupado por la enseñanza debido a su 
sólida conciencia sobre la finalidad práctica y social que debe tener el saber: J. M. Castro y Calvo (1945, p. 9). Sobre esto se puede ver, más recientemente, la introducción de María Jesús Lacarra en el monográfico colectivo, dirigido por ella misma, sobre don Juan Manuel y su obra en el año 2014: M. J. Lacarra (2014, pp. 5-15).

2 Sobre esta consideración resultan ilustrativos los capítulos quinto y sexto del monográfico de C. González Mínguez (1995), principal investigador sobre Fernando IV, y que versan, respectivamente, sobre "la victoria de la nobleza" y el "fracaso reconquistador y confirmación del triunfo de la nobleza". En el caso de Alfonso XI, su actuación estuvo dominada por los consejeros regios hasta el año 1328. Sobre ello puede verse la sección que Alejandra Recuero (2016) le dedicó a "el tiempo de los privados (1325-1328)".Se puede ver, también: C. González Mínguez (2012, pp. 149-156).

3 Se puede ver cómo, por ejemplo, a través de las crónicas de la Sancho IV y de Fernando IV se construye una imagen idealizada de doña María de Molina como infanta o como reina difamada de forma injusta por adversarios políticos como serían, por ejemplo, los infantes don Juan a don Enrique, dos personajes altamente conflictivos durante la minoría de edad y el reinado de Fernando IV (Gómez Redondo, F. 2009, pp. 72-73).

4 Nos basamos aquí en la comprensión del bagaje cultural desde el planteamiento contextual de la Historia Intelectual británica. Así, por ejemplo, John Pocock (2011) definió el "concepto de tradición" como "el conjunto de formas de hablar, comportarse y pensar políticamente heredado de nuestro pasado social" (p.21). Un planteamiento similar podría ser el de Reinhart Koselleck (2006) cuando habla de las estructuras de repetición como una realidad cambiante sobre la que se desarrollan los acontecimiento históricos y culturales para, sobre las mismas pautas, dar lugar a realidades nuevas.

5 Sobre la estructura de «El libro del caballero y el escudero» y sobre la presentación de la trama entre los capítulos I y III puede verse el estudio de Barry Taylor (1984, pp. 51-56).

6 En este sentido encontramos distintas alusiones al concepto de justicia en «El libro de los estados»: "et, señor infante, devedes saber que la justicia non es tan solamente en matar omnes, ante es en muchas otras cosas, que así commo por justiçia matan el que lo mereçe, así es justiçia tollerle algún mienbro si lo meresçe, o darle fanbre o sed o otros tormentos, segund sus merecimientos, o darle presones graves o ligeras, segund el yerro en que cayó (...). Et sil dan la pena más o menos que deen, o dan por yerro la pena que devían dar por el otro, non fazen justiçia, ca justiçia es dar a cada uno lo suyo" (Don Juan Manuel, 2014, p.469).

7 También son frecuentes las alusiones a la virtud del "buen seso" en la segunda parte de «El libro del conde Lucanor» (Don Juan Manuel, 2014, pp. 680-686).

8 A partir del trabajo de Leonardo R. Funes, el trabajo intertextual de don Juan Manuel y la apertura del relato en el «Libro de los Estados», comprendemos esta sección de capítulo como el punto en el que se establecen las condiciones del relato y se enlaza la escena inicial con el arranque de la historia (Funes, 1988, p. 105).

9 Aunque se puede apreciar también en la producción didáctico-política, la corresponsabilidad es una característica que la profesora Inés Fernández-Ordóñez (2000) ha resaltado en la producción cronística postalfonsí del periodo de Sancho IV.

10 La omisión de información de una de las estrategias que se pueden emplear para variar el contenido ideológico que se transmite a través del significado de un discurso. Sobre esto se puede ver el trabajo de T. A. van Dijk (2003, p. 58-65).

\section{BY-NC-SA}

